\title{
Social and Financial Efficiency of Microfinance Institutions in Pakistan
}

\author{
ZAHOOR KHAN and JAMALLUDIN SULAIMAN
}

\section{INTRODUCTION}

Financial efficiency and profitability of 'for profit' institutions have been traditionally measured with the help of financial ratios [Hassan and Sanchez (2009)]. However, financial ratios are inappropriate to investigate the sources of inefficiency, estimate financial or social efficiency with multiple inputs and outputs, and to decompose the sources of efficiency or inefficiency into technical, technological and scale efficiencies or inefficiencies respectively [Hassan and Sanchez (2009)]. Microfinance Institutions (MFIs) are special institutions, which simultaneously consider their social role to uplift the marginalised community members along with their commercial objective to secure self-sustainability. In standard literature this phenomenon is coined MFIs as being "double bottom line" institutions. [Gutierrez-Nieto, Serrano-Cinca, and Mar Molinero (2007); Gutiérrez-Nieto, Serrano-Cinca, and Molinero (2007)]. This simultaneity differentiates MFIs from conventional financial institutions. The achievement of socioeconomic efficiency is indispensable for MFIs to operate independently and on a wider scale. Thus investigation of socioeconomic efficiency of MFIs is important for monitoring and optimal policy implications.

Efficiency assessment techniques are broadly divided into parametric; such as Stochastic Frontier Analysis (SFA), Thick Frontier Analysis (THA) etc., and nonparametric techniques such as Data Envelopment Analysis (DEA) [Berger and Humphrey (1997); Gutiérrez-Nieto, et al. (2007)]. According to Berger and Humphrey (1997) the popular efficiency assessment technique is DEA. This technique does not assume any prior specific shape of distribution and is also free from specific functional form. In spite of the mentioned strengths of DEA, it also has some demerits as well. Before investigating efficiency of Pakistani MFIs, it is important to consider the limitation of DEA. Otherwise it may yield misleading results. For example, an inefficient DMU may become efficient and vice versa because of inappropriate specification of the model or irrelevant input or output variables [Gutiérrez-Nieto, et al. (2007)]. How to avoid or minimise the biasedness of this technique is a question of central importance for researchers and policy institutions? The DEA technique identifies an efficient MFI based on extreme

Zahoor Khan<zahoor.khan@imsciences.edu.pk> is Assistant Professor, Institute of Management Sciences, Hayatabad, Peshawar. Jamalludin Sulaiman is Professor, School of Social Sciences, Universiti Sains Malaysia, Malaysia. 
information therefore, it is unsafe to conclude that an MFI is efficient or otherwise based on a single input-output specification. To deal with this issue, this paper attempts to identify an efficient MFI based on all possible and theoretically important combinations of input and output variables. This idea was developed by Cinca and Molinero (2004). There are different statistical techniques such as "Factor Analysis" to identify factor inputs or outputs, which are more important than other combinations of input and output variables for model specifications.

Pakistan initiated microfinance programmes in 1980s. The Agha Khan Rural Support Programme (AKRSP) and the Orangi Pilot Project were the first microcredit programmes initiated in Pakistan. Today microfinance sector in Pakistan consists of; Microfinance banks, Rural Support Programmes, NGOs, Islamic microfinance NGOs and specialised MFIs. Major changes have been observed in the microfinance sector in Pakistan. First, there were no practices of the provision of other financial services like micro-insurance, deposit; micro-pensions etc., except microcredit but in recent days MFIs provide a set of financial products and policies. Second, microcredit programmes were imitated to help the poor and marginalised people without any commercial objectives but todays' most of the MFIs have changed their intentions and now they are looking for both: commercial gains and social success. Third, microfinance programmes in Pakistan were multidimensional in nature but todays' microfinance programmes are more specific and specialised.

Pakistan is one of the developing countries, which recognised the importance of microfinance as a strong tool for socioeconomic uplifting of the poor and financially marginalised segments since the early 80 's. Although, the country has initiated the efforts for the last 30 years against poverty and gender disparity; however, the desired outcome has not been achieved. Under the "Microfinance Strategy 2007", the state bank of Pakistan set a target to reach 3 million borrowers until the end of 2010. Further, the target is expected to grow from 3 million to 10 million by the end of 2015 [SBP (2011)]. ${ }^{1}$ However, until the end of fiscal year 2012-13, around 2.43 million poor have only been reached by microfinance institutions [Mixmarket (2012)].

This paper aims to gauge financial and social efficiency of Pakistani MFIs across the country to know the underlying factors which make a particular DMU efficient or otherwise. These factors have been investigated in different dimensions such as organisational characteristics, cost and financial structure of MFIs, the ability of MFIs to generate maximum profit, disburse maximum loans, and targeting "poorer and financially marginalised' community members.

\section{THEORETICAL FRAMEWORK OF THE STUDY}

The roots of micro-financing, to facilitate the poor by providing small loans for productive utilisation and self-employment, can be traced back to philosophical concern of conceptualising poverty as lacking of access to financial capital [EngbergPedersen and Munk Ravnborg (2010); Hulme and Shepherd (2003)]. According to this concept poor are assumed to be productive, capable of running their own small businesses and creditworthy to payback their loans. This idea initiated the extension of microcredit to the poor at different formal and informal levels [Ledgerwood (1999)]. Informal credit has remained a more dominant source for the poor who

${ }^{1}$ Please see Table 1.3 and 1.4. 
were not able to produce physical collateral for conventional financial institutions [Rhyne and Christen (1999)]. In nutshell, conceptualisation of poverty as lack of access of the poor to financial capital, the extension of financial capital for selfemployment and productive utilisation of credit, marginalisation of poor by the traditional banks due to lack of physical collateral, exploitation of the poor by informal credit sources and focus of business models on alleviation of poverty are some of the factors which initiated microfinance activities across the globe.

The operations of microfinance institutions can be broadly observed into two contexts. First, Microfinance institutions can be observed as financial intermediaries such as they collect deposits from the clients and non-clients, they provide saving facilities to the clients and then mobilise the funds among the clients who need them [Christen and Drake (2002); Qayyum and Ahmad (2006)]. In this context, microfinance institutions are more or less similar to conventional banks in terms of their operations. Second, microfinance institutions can be treated as production units [Gonzalez (2007); Haq (2008)]. MFI institutions use certain inputs such as credit officers, capital and produce outputs such disbursement of loans, generating revenue and targeting the poor clients [Armendáriz and Morduch (2010); Qayyum and Ahmad (2006)]. Production approach seems more appropriate than intermediary approach because all MFIs do not provide the facility of saving and deposits, except microfinance banks (which is only one kind of MFIs) thus, this approach does not fit to maximum MFIs [Gutiérrez, Serrano-Cinca, and Molinero (2007)]. Efficiency theories, to test financial or social efficiency and overall performance of microfinance thus do not seem good in production approach. The neo classical theory of production and production efficiency seems more suitable when the MFIs are assumed as productive units (such as firms), while they are producing almost same products, working in the same regulatory and environment, using more or less same inputs. Based on the assumptions of neoclassical economists, producers always operate efficiently in terms of both technical aspects and economic aspects as well [Kokkinou (2010)]. For example, technical efficiency means optimisation by not wasting productive resources while economic efficiency means producers optimise by solving allocation problem involving prices. The difference in production may result from the differences in;

(i) Technology of production.

(ii) Differences in the efficiency of the production process.

(iii) Differences in the environment where production is taking place.

There is a fair chance of difference in production even when technology and production environment are almost the same, firms or industries may exhibit different productivity levels due to differences in their production efficiency [Kokkinou (2010)]. Thus, this study attempt to investigate social and financial efficiency of the MFIs under the assumption of constant return to scale (input oriented CCR-model) and variable return to scale (input oriented BCC-model). The following Figure 1 shows theoretical framework of the study. 


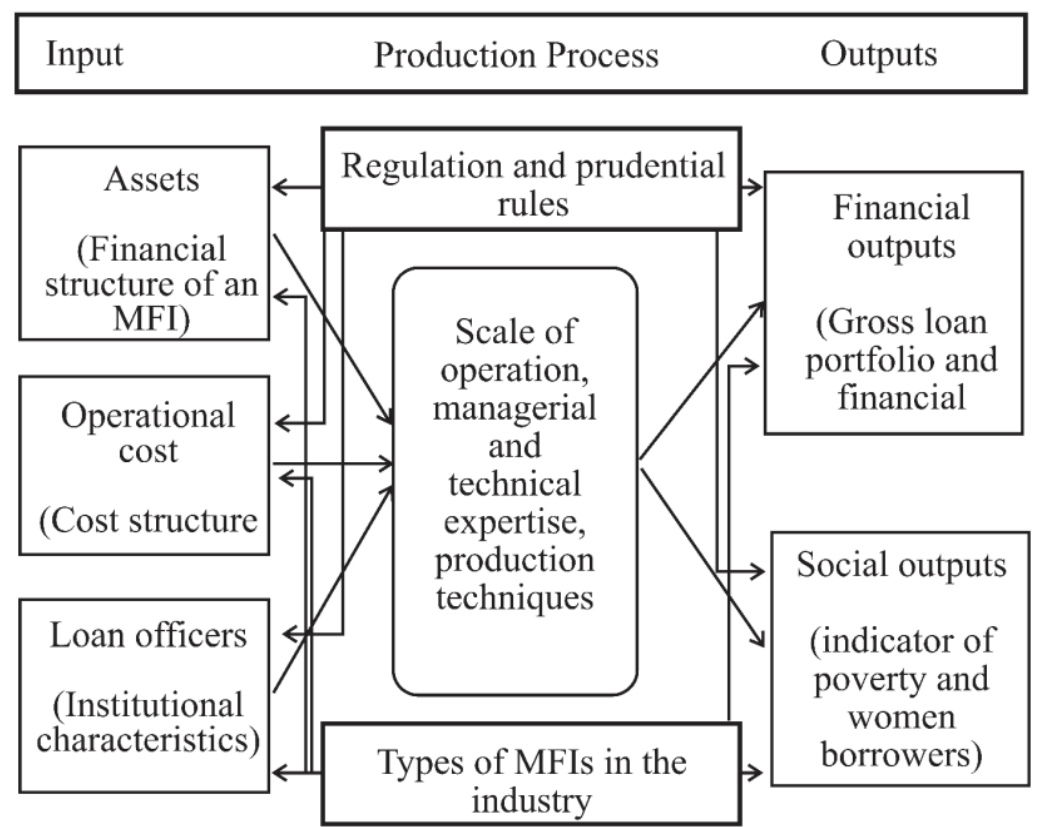

Fig. 1. Theoretical Framework of the Study

Inputs: Factors which are used to produce something or deliver a service. These can affect the production process, Industry characteristics can be affected from external factors.

Production Process: This is a link between factors input and output. This may compromise the quality and quantity of inputs, exogenous factors, and industry characteristics while it can affect output and industry characteristics in turn. This may encompasses production technology, internal environment, scale of production.

Output: This may be in the form of physical production or the provision of service. Output is affected by inputs through the production process and affects organisational performance.

External Factors: Factors which are exogenous such as intervention of the government through regulation polices, donors, rating agencies. These factors may affect the whole process-starting from input selection to operational performance.

Industry Characteristics: Industry characteristics such as the number of FMIs in the industry, capital or labour intensity of the industry, what product is being produced or what service is being offered. Industry characteristics are affected by and also affect inputs, production process, output and organisational performance.

\section{MATERIAL AND METHODS}

The sample size of the study consists of all Pakistani MFIs, available with latest complete information on Microfinance Information Exchange (MIX). The study therefore; uses cross sectional data for the year 2012. The selection of input and output variables is based on the literature [Gutierrez-Nieto, et al. (2007); Hassan and Sanchez (2009); Mamiza Haq, Michael, and Shams (2010)]. After going through the literature 
three inputs (Assets, Operating Costs (OC) and Loan Officers (LO)) and four outputs (two financial variables such as Gross Loan Portfolio (GLP), Financial Revenue (FR) and two social variables such as Women Borrowers (WB) and indicator of poorer clients' index (P)) selected to investigate how efficiently MFIs in Pakistan transform the selected inputs to achieve their twin objectives; optimal social and financial efficiency. Based on Gutiérrez, et al. (2007) calculating poverty index requires to weight each MFI as; $\mathrm{w}=[\{1-(\mathrm{Ki}-\mathrm{Min}(\mathrm{k})) /$ Range of $\mathrm{K}]$ where $i$ represents the number of a particular MFI. Min (k) is the minimum of Average Loan per Borrower (ALPB) while $\max (\mathrm{k})$ is the maximum of ALPB. The range represents the difference between maximum and minimum $(\operatorname{Max}(\mathrm{K})$ - Min $(\mathrm{k}))$. Based on the weight (w) assigned to each MFI, the indicator of poverty has been thus obtained. Pi is an index of support of the poor, based on ALPB. This index favours those MFIs which have smaller ALPB. Pi for a specific MFI can be obtained when its weight (w) is multiplied by number of borrowers $(\mathrm{B}) ; \mathrm{wB}=[\{(1-(\mathrm{Ki}-\operatorname{Min}(\mathrm{k}) /$ Range of $\mathrm{K}\} * \mathrm{~B}]$. It is a combination of two outreach indicators; width of outreach (number of borrowers) and depth of outreach (ALPB). Women borrowers and poverty index, both, are used as social indicators of MFIs.

MFIs in Pakistan consist of seven specialised microfinance banks, three NonBanking Financial Institutions (NBFI) and nineteen NGOs. Keeping into consideration the limitation of same input and output variables for DEA models, this study adopted $a$ production approach and avoided deposits with MFIs as input because the majority MFIs (particularly, NGO are mostly not regulated and thus are not able to mobilise savings and collect deposits from their clients) do not provide the facilities of saving or deposit collections. The following Table 1 represents input and output variables, their definitions and measurement units.

Table 1

Inputs and Outputs and Their Definitions and Measurement

\begin{tabular}{|c|c|c|c|}
\hline Symbol & Variable Name & Variable Definition & Unit \\
\hline Input (A) & Total Assets & Total of all net asset accounts & $\$$ \\
\hline \multirow[t]{2}{*}{ Input (B) } & Operating Cost & Expenses related to operations, such as all personnel & \\
\hline & & $\begin{array}{l}\text { Expenses, rent and utilities, transportation, office supplies, and } \\
\text { depreciation }\end{array}$ & $\$$ \\
\hline Input (C) & $\begin{array}{l}\text { Number of loan } \\
\text { officers }\end{array}$ & $\begin{array}{l}\text { The number of individuals who are actively employed by the } \\
\text { MFI to disburse loan and collect repayments. }\end{array}$ & Number \\
\hline Output (1) & $\begin{array}{l}\text { Gross loan } \\
\text { portfolio }\end{array}$ & $\begin{array}{l}\text { Gross loan portfolio outstanding principal balance of all of the } \\
\text { MFI's outstanding loans including current, delinquent and } \\
\text { restructured loans, but not loans that have been written off. }\end{array}$ & $\$$ \\
\hline Output (2) & Financial revenue & $\begin{array}{l}\text { Financial revenue generated from the gross loan portfolio and } \\
\text { from investments plus other operating revenue }\end{array}$ & $\$$ \\
\hline Output (3) & $\begin{array}{l}\text { Indicator of Benefit } \\
\text { to the poorest }\end{array}$ & $\begin{array}{l}\text { Poverty Index, it is a combination of two outreach indicators; } \\
\text { width of outreach (number of borrowers) and depth of outreach } \\
\text { (ALPB). }\end{array}$ & $\$$ \\
\hline Output (4) & $\begin{array}{c}\text { Number of women } \\
\text { borrowers }\end{array}$ & Number of active borrowers who are female & Number \\
\hline
\end{tabular}

Source: Adopted from [Gutiérrez, et al. (2007); Gutierrez and Goitisolo Lezama (2011)].

Data envelopment analysis efficiency score, with the help of the selected input and output variables, is estimated under BCC [Banker, Charnes, and Cooper (1984)] and 
CCR [Charnes, Cooper, and Rhodes (1978)] input based models through 19 different specifications. Each specification of input/s and output/s represents a unique combination to reveal the sources of efficiency or inefficiency for each MFI. For example, the input variables represent three dimensions; asset (capital structure), operating cost (cost structure) and loan officers (the quality of human resources) and the output variables represent financial indicators (gross loan portfolio and financial revenue) and social indicators (indicator of poverty and targeting the women clients). First 12 models (A1, $\mathrm{A} 2, \mathrm{~A} 3, \mathrm{~A} 4, \mathrm{~B} 1, \mathrm{~B} 2, \mathrm{~B} 3, \mathrm{~B} 4, \mathrm{C} 1, \mathrm{C} 2, \mathrm{C} 3$, and $\mathrm{C} 4)$ represent a corresponding one to one relationship among the input and output variables. This will help to identify the channels of efficiency for each MFI. The next four models (ABC1, ABC2, ABC3 and ABC4) represent the combinations of all inputs with respect to financial and social indicators. Subsequent two models ( $\mathrm{ABC} 12$ and $\mathrm{ABC} 34)$ represent financial and social efficiency models. These are more comprehensive models of financial and social efficiency than the previous models because they take into consideration all input and output variables, which make an MFI efficient or otherwise. The final model (ABC1234) represents overall efficiency based on all the selected input and output variables.

These models were estimated through DEA, a non-parametric technique, used for calculation of social and financial efficiency without prior information about the shape of the distribution of a data set. This technique allows the researchers to calculate social or financial efficiency with multiple inputs and outputs [Gutiérrez, et al. (2007); Gutierrez and Lezama (2011); Haq, Skully, and Pathan (2010); Kabir and Benito (2009)]. This technique is equally beneficial for commercial and non-commercial DMUs. Both inputoriented (IO) and output-oriented (OO) versions of the DEA methodology have been applied to the data for the sake of efficiency score comparison. In order to specify the mathematical formulation of the IOM, if there are K MFIs (in the language of DEA it is called DMUs) using $\mathrm{N}$ inputs to produce $\mathrm{M}$ outputs then inputs are denoted by $\mathrm{x}_{\mathrm{jk}}$ $(j=1 \ldots . n)$ and the outputs are represented by $y_{i k}(i=1 \ldots \ldots . m)$ for each MFI $k(k=1 \ldots \ldots . K)$. The efficiency of the DMU can be measured as shown by [Coelli, Rao, and Battese (1998); Qayyum and Ahmad (2006); Shiu (2002); Worthington (1999)].

Technical Efficiency $=($ Sum of weighted output/Sum of weighted input $)$

$$
=\mathrm{TE}_{\mathrm{k}}=\theta=\begin{array}{lllll}
\sum_{i=1}^{m} u_{i} y_{i k} / \sum_{j=1}^{n} v_{j} x_{j k} & \ldots & \ldots & \ldots & \ldots
\end{array}
$$

Where $y_{i k}$ is the quantity of the $i^{\text {th }}$ output produced by the $\mathrm{k}^{\text {th }}$ MFI, $\mathrm{x}_{\mathrm{js}}$ is the quantity of $\mathrm{j}^{\text {th }}$ input used by the $\mathrm{k}^{\text {th }}$ MFI, and $\mathrm{u}_{\mathrm{i}}$ and $\mathrm{v}_{\mathrm{j}}$ are the output and input weights respectively. The DMU maximises the efficiency ratio, TEk, subject to;

$$
\left(\sum_{i=1}^{m} u_{i} y_{i k} / \sum_{j=1}^{n} v_{j} x_{j k}\right) \leq 1 \text {, where } u_{j} \text { and } v_{j} \geq 0 \quad \ldots \quad \ldots \quad \ldots
$$

The above Equation (2) indicates that efficiency measures of an MFI cannot exceed 1, and the input and output weights are positive. The weights are selected in such a way that the MFI maximises its own efficiency. To select optimal weights the following mathematical programming (output-oriented) is specified [Coelli, et al. (1998); Qayyum and Ahmad (2006); Shiu (2002); Worthington (1999)].

\section{CCR AND BCC INPUT ORIENTED MODELS}


Input-orientated DEA model looks at the amount by which inputs can be proportionally reduced, where the amount of output is supposed to be fixed. On the contrary, the output-orientated model looks at the amount by which outputs can be proportionally expanded, where the amount of input is supposed to be fixed. The DEA can be conducted under the assumption of constant returns to scale (CRS) or variable returns to scale (VRS)

$$
\operatorname{Min} \theta=\theta o-\varepsilon\left(\sum_{i=1}^{m} s_{i}{ }^{+}+\sum_{j=1}^{n} s_{j}^{-}\right) \quad \ldots \quad \ldots \quad \ldots \quad \ldots
$$

Subject to

$$
\begin{aligned}
& \sum_{j=1}^{n} x_{i k} \lambda_{k}+s_{j}^{-}=\theta_{x_{i o},} j=1, \ldots . . n \\
& \sum_{j=1}^{m} y_{j k} \lambda_{k}-s_{i}{ }^{+}=y_{x_{i o},} i=1, \ldots . . m \\
& \lambda_{j}, s_{j}{ }^{-}, s_{i}{ }^{+} \geq 0, \varepsilon>0, k=1, \ldots \ldots . s
\end{aligned}
$$

Where $\theta o$ is the proportion of DMUo's inputs needed to produce a quantity of output equivalent to its benchmarked DMU output identified and weighted by the $\lambda \mathrm{i}$. $\mathrm{S}_{\mathrm{i}}{ }^{-} s r+\mathrm{is}$ the slack variables of input and output respectively. $\lambda_{\mathrm{j}}$ is a (n $\left.\mathrm{x} 1\right)$ column vector of constants and indicate benchmarked DMUs.

The CCR model developed by Charnes, et al. (1978) estimate the efficiency of DMU with the assumption of Constant Return to Scale (CRS). This assumption may fail in imperfect markets. The CRS assumption is only appropriate when all firms are operating at an optimal scale. The use of the CRS specification when all firms are not operating at the optimal scale results in measures of Technical Efficiency (TE) which are confounded by scale efficiencies (SE). The use of the VRS specification permits the calculation of TE devoid of these SE effects.SE can be calculated by estimating both the CRS and VRS models and looking at the difference in scores. VRS model is essentially the CRS with an additional constraint added to the LP problem.

The BCC model developed by Banker, et al. (1984) is a modified version of CCR. This model helps to investigate scale efficiency. If striction $\sum_{k=1}^{s} \lambda_{k}=1$, is connected, then CCR model becomes BCC [Banker, Charnes, Cooper (1984)] model.

The modified form of CCR can be written as:

$$
\operatorname{Min} \operatorname{TE}(\theta)=\theta o-\varepsilon\left(\sum_{i=1}^{m} s_{i}{ }^{+}+\sum_{j=1}^{n} s_{j}^{-}\right) \quad \ldots \quad \ldots \quad \ldots \quad \ldots
$$

Subject to

$$
\begin{aligned}
& \sum_{j=1}^{n} x_{i k} \lambda_{k}+s_{j}^{-}=\theta_{x_{i o},} j=1, \ldots . n \\
& \sum_{j=1}^{m} y_{j k} \lambda_{k}-s_{i}^{+}=y_{x_{i o},} i=1, \ldots . . m \\
& \sum_{k=1}^{s} \lambda_{k}=1 \\
& \lambda_{j}, s_{j}^{-}, s_{i}{ }^{+} \geq 0, \varepsilon>0, k=1, \ldots \ldots . n
\end{aligned}
$$

\section{ESTIMATION TECHNIQUES AND METHODOLOGICAL CONCERNS}

Following the model specification suggested by Cinca and Molinero (2004) the study estimated DEA efficiency for each feasible specification. Thus 19 different specifications of input and output variables have been estimated. Finally, super efficiently for all specified models have been estimated to rank the efficient MFIs [Lovell and Rouse 
(2003)]. In terms of input oriented models, super efficiency of a DMU represents the maximum possible proportional increase in an input vector retaining the DMU efficiency [Khodabakhshi (2007)].The DEA efficiency and super efficiency of all selected models have been estimated in the Efficiency Measurement System (EMS 1.3 version). The following Tables 2 and 3 show the results of various DEA efficiency models under the BCC and CCR models. The BCC models are used to estimate pure technical efficiency while CCR models are used to estimate overall technical efficiency. The ratio of CCR and BCC are then used to estimate scale efficiency and returns to scale [Banker and Thrall (1992); Ruggiero (2011)]. The maximum value of a technical or pure technical efficient MFI is 100. It means that the MFI is 100 percent efficient to transform inputs into outputs. Any MFI for which the efficiency score is less than 100 is considered inefficient in managerial and technical aspects [Charnes, et al. (1978)].

\section{RESULTS AND DISCUSSION}

Tables 2 and 3 show efficiency scores, which resulted from input oriented CCR and BCC models for 29 MFIs with 19 specifications, to comprehend that what makes an MFI efficient or otherwise. The last three columns (ABC12, ABC34, ABC1234) of the Tables 2 and 3 present financial, social and overall efficiency respectively. None of the MFIs is 100 percent efficient under all specifications. A total of 10 out of 29 MFIs while only 2 FMIs were found 100 percent efficient on social, financial and overall efficiency dimensions under BCC and CCR models respectively. An MFI, which is efficient on social or financial dimensions is also 'overall efficient'. Under both model structures (BCC \& CCR) the number of efficient MFIs increases when it has used more input and output variables. This is evident from the last three columns of the Tables 2 and 3. As these models involve more input and output variables, therefore the numbers of efficient MFIs are also higher than the rest of models' results.

The efficiency result of MFIs also varies across the return to scales. Under the CCR models, assuming a constant return to scale, only two out of twenty nine MFIs are overall efficient (means efficient on social, financial and overall dimensions-including all input and output variables) while under BCC models, assuming variable returns to scale, ten MFIs are efficient on social, financial and overall dimensions. This finding of the study cautions about misleading results, resulting from a single specification of DEA efficiency estimated for a DMU. Notwithstanding, such a single specification may not reveal the sources of efficiency or inefficiencies. The difference between the results of the CCR and BCC models of efficiency reveals the difference between managerial, technical and scale efficiencies. The MFIs, which are socially, financially and overall efficient under CCR models such as ASA- Pakistan and Orangi are at least efficient by either managerial or scale dimensions. Relaxing the assumption of constant return to scale enhanced the number of efficient MFIs. This reflects that majority of MFIs are efficient based on the managerial and technical skills but not on the scale dimensions. Thus the difference between BCC and CCR efficiency models reveal the sources of inefficiency , which resulted from the scale of the DMUs. The findings reveal that 2 out of 10 efficient MFIs, based on three comprehensive specifications (ABC12, ABC 34, $A B C$ 1234) under CCR are efficient based on managerial and scale dimensions (Please see Table 3 last three columns). Estimating efficiency of DMUs with a single

specification and from full dataset will not reveal that how a particular DMU has 
achieved efficiency? Similarly, if a DMU is inefficient we shall not be able to detect the reasons of inefficiency.

Super efficiency for all 19 specifications of models has been estimated to know the rank of the efficient MFIs. As super efficiency of inefficient MFIs remains the same therefore, this technique only helps to rank the efficient MFIs [Scheel (2000)]. Based on the CCR input efficiency model, the super efficiency of Oranagi (an NGO based MFI) is 216.60 percent followed by ASA- Pakistan (an NFBI) with a 120.90 percent score. It can be interpreted as keeping the same output level; an increase in the inputs usage by Orangi and ASA- Pakistan by 116 percentage points and 20 percentage points respectively will not affect the efficiency level of these MFIs.

\section{CONCLUSION AND POLICY IMPLICATIONS}

The assessment of MFIs' efficiency is imperative for all stakeholders for optimal policy measures. Data envelopment analysis is a popular non-parametric, non-stochastic, liner programing based efficiency technique. This paper concentrates on the technical aspects of DEA efficiency score that how it varies across the selection of inputs and outputs, the number of inputs or outputs and the selection of DEA estimation technique. The sample size of this study consists of all MFIs in Pakistan. We have modelled all feasible and meaningful specifications. After 19 different specifications with the help of three input and four output variables, representing various dimensions of MFIs such as cost structure, financial structure and organisational characteristics, we have used input oriented BCC and CCR data envelopment analysis oriented models. We have also estimated super efficiency for all MFIs to rank them according to their potential. This study attempted to investigate financial and social level of efficiency of MFIs and to gauge tracks to efficiency.

The study attempted to achieve the required objectives using appropriate methodology. The study used Data Envelopment Analysis technique to investigate social and finical efficiency. The findings of the study revealed that NGOs and NBFI were more efficient, based on the achievements of social and financial objectives than microfinance banks. Financial and social efficiency of MFIs were estimated by two ways to reveal information about 'managerial and technical' aspects of MFIs. The study revealed that none of the microfinance institutions was found 100 percent efficient under all financial and social efficiency models. There were 13 MFIs, which were pure technically efficient in financial aspects out of the 29 MFIs. Bukhsh foundation scored highest ( 77.7 percent) and remained financially efficient under 15 of 19 different pure technical efficiency models. Subsequently, non-banking financial institutions and microfinance banks stood second in financial efficiency ranking (55.5 percent) based on pure technical score.

Like financial performance of MFIs, there was also a difference in social performance of MFIs, which resulted from variation in institutional characteristics. Twelve MFIs were found socially efficient based on input oriented pure technical efficiency models. Out of total socially efficient MFIs, nine were NGOs, one microfinance bank (Khushali bank) and two non-banking financial institutions (ASAPakistan, Orix leasing). The study reveals and recommends the following; 
Table 2

DEA Efficiency of MFIs Based on BCC Input Oriented Models

\begin{tabular}{|c|c|c|c|c|c|c|c|c|c|c|c|c|c|c|c|c|c|c|c|}
\hline DMUs & $\mathrm{A} 1$ & A2 & A3 & A4 & B1 & B2 & B3 & B4 & $\mathrm{C} 1$ & B2 & $\mathrm{C} 3$ & $\mathrm{C} 4$ & $\mathrm{ABC} 1$ & $\mathrm{ABC} 2$ & $\mathrm{ABC} 3$ & $\mathrm{ABC} 4$ & $\begin{array}{c}\mathrm{ABC} \\
12 \\
\end{array}$ & $\begin{array}{c}\mathrm{ABC} \\
34\end{array}$ & $\begin{array}{l}\mathrm{ABC} \\
1234 \\
\end{array}$ \\
\hline Akhuwat & 54 & 33 & 41 & 15 & 45 & 37 & 43 & 18 & 21 & 10 & 30 & 16 & 61 & 38 & 52 & 22 & 61 & 52 & 61 \\
\hline Apna MF Bank & 83 & 74 & 9 & 10 & 42 & 59 & 15 & 15 & 34 & 26 & 13 & 14 & 90 & 79 & 20 & 20 & 91 & 20 & 91 \\
\hline ASA Pakistan & 100 & 100 & 100 & 100 & 79 & 90 & 100 & 100 & 22 & 17 & 59 & 82 & 100 & 100 & 100 & 100 & 100 & 100 & 100 \\
\hline Asasah & 8 & 53 & 79 & 79 & 16 & 16 & 18 & 23 & 43 & 30 & 52 & 78 & 88 & 56 & 100 & 100 & 88 & 100 & 100 \\
\hline BRAC - PAK & 73 & 95 & 58 & 60 & 20 & 34 & 20 & 24 & 14 & 14 & 23 & 38 & 73 & 95 & 58 & 60 & 95 & 60 & 95 \\
\hline Buksh Foundation & 100 & 100 & 100 & 100 & 29 & 29 & 29 & 29 & 100 & 100 & 100 & 100 & 100 & 100 & 100 & 100 & 100 & 100 & 100 \\
\hline $\mathrm{CSC}$ & 62 & 85 & 31 & 38 & 22 & 47 & 15 & 22 & 39 & 40 & 31 & 52 & 72 & 93 & 48 & 62 & 93 & 62 & 93 \\
\hline CWCD & 82 & 80 & 28 & 14 & 28 & 41 & 15 & 15 & 25 & 21 & 18 & 13 & 82 & 80 & 30 & 21 & 82 & 30 & 82 \\
\hline DAMEN & 77 & 89 & 30 & 4 & 59 & 99 & 27 & 50 & 69 & 60 & 41 & 100 & 100 & 100 & 54 & 100 & 100 & 100 & 100 \\
\hline FFO & $79 \%$ & 75 & 63 & 66 & 32 & 42 & 30 & 35 & 32 & 28 & 35 & 47 & 81 & 79 & 69 & 72 & 81 & 72 & 81 \\
\hline FMFB - Pakistan & 48 & 68 & 10 & 5 & 45 & 64 & 12 & 7 & 45 & 45 & 26 & 19 & 79 & 83 & 26 & 19 & 83 & 31 & 85 \\
\hline GBTI & 33 & 40 & 10 & 12 & 37 & 61 & 25 & 25 & 58 & 56 & 39 & 46 & 61 & 81 & 41 & 46 & 81 & 46 & 81 \\
\hline JWS & 69 & 74 & 36 & 41 & 29 & 51 & 20 & 30 & 37 & 31 & 29 & 52 & 79 & 80 & 52 & 64 & 82 & 64 & 82 \\
\hline Kashf Bank & 57 & 81 & 1 & 1 & 22 & 36 & 1 & 1 & 52 & 53 & 5 & 5 & 82 & 98 & 5 & 5 & 98 & 5 & 98 \\
\hline Kashf Foundation & 100 & 98 & 100 & 100 & 63 & 65 & 85 & 100 & 27 & 19 & 75 & 100 & 100 & 98 & 100 & 100 & 100 & 100 & 100 \\
\hline Khushali Bank & 100 & 76 & 67 & 11 & 83 & 55 & 39 & 10 & 61 & 42 & 100 & 39 & 100 & 71 & 100 & 28 & 100 & 100 & 100 \\
\hline NRSP & 99 & 84 & 100 & 50 & 100 & 100 & 100 & 95 & 17 & 12 & 100 & 39 & 100 & 100 & 100 & 95 & 100 & 100 & 100 \\
\hline NRSP Bank & 63 & 85 & 13 & 3 & 59 & 80 & 16 & 4 & 43 & 41 & 27 & 7 & 96 & 100 & 30 & 7 & 100 & 30 & 100 \\
\hline Orangi & 6 & 32 & 50 & 5 & 100 & 86 & 100 & 18 & 99 & 46 & 100 & 28 & 100 & 88 & 100 & 30 & 100 & 100 & 100 \\
\hline Orix Leasing & 62 & 53 & 45 & 45 & 46 & 63 & 42 & 54 & 65 & 50 & 65 & 100 & 82 & 76 & 80 & 100 & 82 & 100 & 100 \\
\hline POMFB & 18 & 42 & 6 & 4 & 12 & 40 & 7 & 7 & 28 & 41 & 20 & 16 & 29 & 54 & 20 & 16 & 54 & 20 & 54 \\
\hline PRSP & 28 & 52 & 20 & 11 & 29 & 72 & 26 & 16 & 15 & 20 & 21 & 16 & 35 & 78 & 30 & 21 & 78 & 30 & 78 \\
\hline RCDS & 59 & 76 & 34 & 36 & 27 & 58 & 21 & 29 & 36 & 35 & 30 & 54 & 69 & 83 & 53 & 62 & 83 & 62 & 83 \\
\hline SAFWCO & 64 & 61 & 56 & 28 & 35 & 57 & 40 & 28 & 29 & 22 & 33 & 31 & 71 & 66 & 74 & 42 & 73 & 74 & 82 \\
\hline SRSO & 86 & 61 & 48 & 51 & 75 & 68 & 47 & 62 & 47 & 26 & 49 & 89 & 100 & 69 & 72 & 95 & 100 & 95 & 100 \\
\hline SRSP & 85 & 48 & 97 & 94 & 69 & 69 & 69 & 69 & 90 & 80 & 100 & 100 & 100 & 100 & 100 & 100 & 100 & 100 & 100 \\
\hline Sungi & 98 & 79 & 100 & 100 & 100 & 100 & 100 & 100 & 43 & 38 & 52 & 62 & 100 & 100 & 100 & 100 & 100 & 100 & 100 \\
\hline TMFB & 100 & 100 & 1 & 4 & 100 & 100 & 1 & 5 & 100 & 100 & 5 & 27 & 100 & 100 & 4 & 18 & 100 & 18 & 100 \\
\hline TRDP & 83 & 61 & $82 \%$ & 51 & 69 & 81 & 96 & 72 & $31 \%$ & 19 & 54 & 50 & 99 & 81 & 100 & 77 & 99 & 100 & 100 \\
\hline
\end{tabular}


Table 3

DEA Efficiency of MFIs Based on CCR, Input Oriented Models

\begin{tabular}{|c|c|c|c|c|c|c|c|c|c|c|c|c|c|c|c|c|c|c|c|}
\hline DMUs & $\mathrm{A} 1$ & $\mathrm{~A} 2$ & $\mathrm{~A} 3$ & $\mathrm{~A} 4$ & B1 & B2 & B3 & B4 & $\mathrm{C} 1$ & B2 & $\mathrm{C} 3$ & $\mathrm{C} 4$ & $\mathrm{ABC1}$ & $\mathrm{ABC2}$ & $\mathrm{ABC} 3$ & $\mathrm{ABC} 4$ & $\mathrm{ABC} 12$ & $\mathrm{ABC} 34$ & $\mathrm{ABC} 1234$ \\
\hline Akhuwat & 54 & 30 & 34 & 13 & 36 & 36 & 35 & 16 & 19 & 8 & 22 & 15 & 61 & 37 & 52 & 22 & 61 & 52 & 61 \\
\hline Apna MF Bank & 81 & 66 & 5 & 7 & 37 & 55 & 3 & 6 & 24 & 16 & 2 & 7 & 87 & 77 & 6 & 10 & 88 & 10 & 88 \\
\hline ASA Pakistan & 100 & 89 & 82 & 88 & 54 & 90 & 69 & 87 & 21 & 16 & 32 & 62 & 100 & 100 & 99 & 100 & 100 & 100 & 100 \\
\hline Asasah & 77 & 48 & 70 & 73 & 12 & 14 & 17 & 21 & 24 & 13 & 41 & 77 & 84 & 56 & 97 & 100 & 84 & 100 & 100 \\
\hline BRAC - PAK & 73 & 85 & 48 & 53 & 16 & 34 & 16 & 21 & 13 & 13 & 16 & 32 & 73 & 93 & 52 & 57 & 93 & 57 & 93 \\
\hline Buksh Foundation & 60 & 100 & 24 & 19 & 3 & 10 & 2 & 2 & 10 & 13 & 7 & 10 & 60 & 100 & 25 & 20 & 100 & 25 & 100 \\
\hline CSC & 61 & 77 & 28 & 35 & 19 & 45 & 14 & 20 & 27 & 28 & 23 & 52 & 70 & 92 & 47 & 62 & 92 & 62 & 92 \\
\hline CWCD & 78 & 72 & 27 & 7 & 22 & 37 & 12 & 4 & 14 & 11 & 9 & 4 & 78 & 80 & 30 & 8 & 80 & 30 & 80 \\
\hline DAMEN & 77 & 80 & 26 & 36 & 51 & 98 & 26 & 44 & 61 & 52 & 38 & 96 & 100 & 100 & 54 & 96 & 100 & 96 & 100 \\
\hline FFO & 74 & 68 & 59 & 63 & 22 & 37 & 27 & 34 & 15 & 12 & 22 & 43 & 74 & 76 & 67 & 71 & 76 & 71 & 76 \\
\hline FMFB - Pakistan & 39 & 47 & 8 & 5 & 29 & 64 & 9 & 6 & 44 & 44 & 17 & 17 & 58 & 73 & 18 & 17 & 73 & 24 & 73 \\
\hline GBTI & 31 & 36 & 7 & 11 & 25 & 55 & 9 & 16 & 28 & 27 & 12 & 33 & 42 & 56 & 1 & 33 & 56 & 33 & 56 \\
\hline JWS & 68 & 66 & 31 & 37 & 27 & 49 & 19 & 27 & 29 & 23 & 24 & 52 & 77 & 80 & 50 & 64 & 80 & 64 & 80 \\
\hline Kashf Bank & 57 & 71 & 0 & 0 & 16 & 36 & 0 & 0 & 49 & 49 & 0 & 1 & 76 & 90 & 0 & 1 & 90 & 1 & 90 \\
\hline Kashf Foundation & 81 & 71 & 63 & 68 & 40 & 65 & 48 & 62 & 26 & 19 & 38 & 74 & 88 & 83 & 91 & 100 & 90 & 100 & 100 \\
\hline Khushhali Bank & 61 & 51 & 27 & 9 & 32 & 49 & 22 & 9 & 61 & 41 & 50 & 31 & 83 & 65 & 57 & 26 & 86 & 63 & 87 \\
\hline NRSP & 65 & 57 & 38 & 35 & 62 & 100 & 55 & 60 & 16 & 12 & 17 & 29 & 85 & 100 & 6 & 60 & 100 & 65 & 100 \\
\hline NRSP Bank & 51 & 59 & 11 & 3 & 37 & 80 & 12 & 4 & 42 & 40 & 17 & 7 & 68 & 82 & 23 & 7 & 82 & 23 & 82 \\
\hline Orangi & 65 & 29 & 42 & 5 & 100 & 82 & 100 & 14 & 84 & 31 & 100 & 21 & 100 & 84 & 100 & 24 & 100 & 100 & 100 \\
\hline Orix Leasing & 60 & 48 & 39 & 41 & 39 & 59 & 40 & 49 & 44 & 29 & 53 & 100 & 77 & 60 & 79 & 100 & 77 & 100 & 100 \\
\hline POMFB & 17 & 38 & 5 & 2 & 9 & 38 & 5 & 2 & 16 & 29 & 9 & 6 & 23 & 50 & 12 & 6 & 50 & 12 & 50 \\
\hline PRSP & 27 & 47 & 17 & 10 & 23 & 72 & 22 & 15 & 13 & 18 & 15 & 15 & 34 & 73 & 30 & 21 & 73 & 30 & 73 \\
\hline RCDS & 58 & 68 & 30 & 32 & 26 & 57 & 20 & 26 & 29 & 28 & 27 & 53 & 67 & 83 & 51 & 62 & 83 & 62 & 83 \\
\hline SAFWCO & 63 & 55 & 47 & 26 & 34 & 55 & 39 & 25 & 23 & 16 & 32 & 31 & 70 & 65 & 73 & 41 & 71 & 73 & 81 \\
\hline SRSO & 86 & 55 & 40 & 45 & 57 & 67 & 40 & 55 & 43 & 23 & 37 & 76 & 100 & 69 & 70 & 93 & 100 & 93 & 100 \\
\hline SRSP & 66 & 40 & 80 & 75 & 18 & 20 & 33 & 37 & 17 & 9 & 39 & 66 & 69 & 46 & 100 & 96 & 69 & 100 & 100 \\
\hline Sungi & 85 & 75 & 100 & 100 & 46 & 75 & 84 & 100 & 13 & 9 & 28 & 50 & 85 & 84 & 100 & 100 & 85 & 100 & 100 \\
\hline TMFB & 53 & 64 & 1 & 4 & 32 & 72 & 1 & 4 & 100 & 100 & 4 & 23 & 100 & 100 & 3 & 16 & 100 & 16 & 100 \\
\hline TRDP & 82 & 55 & 68 & 45 & 64 & 78 & 81 & 64 & 27 & 15 & 40 & 49 & 98 & 80 & 100 & 77 & 98 & 100 & 100 \\
\hline
\end{tabular}

Source: Authors' own calculation. 
Table 4

DEA Super Efficiency of MFIs Based on CCR Input Oriented Models

\begin{tabular}{|c|c|c|c|c|c|c|c|c|c|c|c|c|c|c|c|c|c|c|c|}
\hline DMUs & A1 & $\mathrm{A} 2$ & A3 & A4 & B1 & B2 & B3 & B4 & $\mathrm{C} 1$ & $\mathrm{C} 2$ & C3 & $\mathrm{C} 4$ & $\mathrm{ABC1}$ & $\mathrm{ABC} 2$ & $\mathrm{ABC} 3$ & $\mathrm{ABC} 4$ & $\mathrm{ABC} 12$ & $\mathrm{ABC} 34$ & $\mathrm{ABC1234}$ \\
\hline Akhuwat & 54 & 30 & 34 & 13 & 36 & 36 & 35 & 16 & 19 & 8 & 22 & 15 & 61 & 37 & 52 & 22 & 61 & 52 & 61 \\
\hline Apna MF BK & 81 & 66 & 5 & 7 & 37 & 55 & 3 & 6 & 24 & 16 & 2 & 7 & 87 & 77 & 6 & 10 & 88 & 10 & 88 \\
\hline ASA Pakistan & 117 & 89 & 82 & 88 & 54 & 90 & 69 & 87 & 21 & 16 & 32 & 62 & 117 & 111 & 99 & 108 & 121 & 108 & 121 \\
\hline Asasah & 77 & 48 & 70 & 73 & 12 & 14 & 17 & 21 & 24 & 13 & 41 & 77 & 84 & 56 & 97 & 106 & 84 & 106 & 106 \\
\hline BRAC - PAK & 73 & 85 & 48 & 53 & 16 & 34 & 16 & 21 & 13 & 13 & 16 & 32 & 73 & 93 & 52 & 57 & 93 & 57 & 93 \\
\hline Buksh Found & 60 & 112 & 24 & 19 & 3 & 10 & 2 & 2 & 10 & 13 & 7 & 10 & 60 & 112 & 25 & 20 & 112 & 25 & 112 \\
\hline CSC & 61 & 77 & 28 & 35 & 19 & 45 & 14 & 20 & 27 & 28 & 23 & 52 & 70 & 92 & 47 & 62 & 92 & 62 & 92 \\
\hline CWCD & 78 & 72 & 27 & 7 & 22 & 37 & 12 & 4 & 14 & 11 & 9 & 4 & 78 & 80 & 30 & 8 & 80 & 30 & 80 \\
\hline DAMEN & 77 & 80 & 26 & 36 & 51 & 98 & 26 & 44 & 61 & 52 & 38 & 96 & 105 & 126 & 54 & 96 & 128 & 96 & 140 \\
\hline FFO & 74 & 68 & 59 & 63 & 22 & 37 & 27 & 34 & 15 & 12 & 22 & 43 & 74 & 76 & 67 & 71 & 76 & 71 & 76 \\
\hline FMFB - Pak & 39 & 47 & 8 & 5 & 29 & 64 & 9 & 6 & 44 & 44 & 17 & 17 & 58 & 73 & 18 & 17 & 73 & 24 & 73 \\
\hline GBTI & 31 & 36 & 7 & 11 & 25 & 55 & 9 & 16 & 28 & 27 & 12 & 33 & 42 & 56 & 16 & 33 & 56 & 33 & 56 \\
\hline JWS & 68 & 66 & 31 & 37 & 27 & 49 & 19 & 27 & 29 & 23 & 24 & 52 & 77 & 80 & 50 & 64 & 80 & 64 & 80 \\
\hline Kashf Bank & 57 & 71 & 0 & 0 & 16 & 36 & 0 & 0 & 49 & 49 & 0 & 1 & 76 & 90 & 0 & 1 & 90 & 1 & 90 \\
\hline Kashf Found & 81 & 71 & 63 & 68 & 40 & 65 & 48 & 62 & 26 & 19 & 38 & 74 & 88 & 83 & 91 & 104 & 90 & 104 & 104 \\
\hline Khushali Bk & 61 & 51 & 27 & 9 & 32 & 49 & 22 & 9 & 61 & 41 & 50 & 31 & 83 & 65 & 57 & 26 & 86 & 63 & 87 \\
\hline NRSP & 65 & 57 & 38 & 35 & 62 & 102 & 55 & 60 & 16 & 12 & 17 & 29 & 85 & 102 & 61 & 60 & 105 & 65 & 108 \\
\hline NRSP Bank & 51 & 59 & 11 & 3 & 37 & 80 & 12 & 4 & 42 & 40 & 17 & 7 & 68 & 82 & 23 & 7 & 82 & 23 & 82 \\
\hline Orangi & 65 & 29 & 42 & 5 & 157 & 82 & 119 & 14 & 84 & 31 & 189 & 21 & 181 & 84 & 209 & 24 & 181 & 209 & 217 \\
\hline Orix Leasing & 60 & 48 & 39 & 41 & 39 & 59 & 40 & 49 & 44 & 29 & 53 & 104 & 77 & 60 & 79 & 108 & 77 & 120 & 120 \\
\hline POMFB & 17 & 38 & 5 & 2 & 9 & 38 & 5 & 2 & 16 & 29 & 9 & 6 & 23 & 50 & 12 & 6 & 50 & 12 & 50 \\
\hline PRSP & 27 & 47 & 17 & 10 & 23 & 72 & 22 & 15 & 13 & 18 & 15 & 15 & 34 & 73 & 30 & 21 & 73 & 30 & 73 \\
\hline RCDS & 58 & 68 & 30 & 32 & 26 & 57 & 20 & 26 & 29 & 28 & 27 & 53 & 67 & 83 & 51 & 62 & 83 & 62 & 83 \\
\hline SAFWCO & 63 & 55 & 47 & 26 & 34 & 55 & 39 & 25 & 23 & 16 & 32 & 31 & 70 & 65 & 73 & 41 & 71 & 73 & 81 \\
\hline SRSO & 86 & 55 & 40 & 45 & 57 & 67 & 40 & 55 & 43 & 23 & 37 & 76 & 106 & 69 & 70 & 93 & 106 & 93 & 106 \\
\hline SRSP & 66 & 40 & 80 & 75 & 18 & 20 & 33 & 37 & 17 & 9 & 39 & 66 & 69 & 46 & 107 & 96 & 69 & 107 & 107 \\
\hline Sungi & 85 & 75 & 121 & 114 & 46 & 75 & 84 & 115 & 13 & 9 & 28 & 50 & 85 & 84 & 122 & 115 & 85 & 122 & 122 \\
\hline TMFB & 53 & 64 & 1 & 4 & 32 & 72 & 1 & 4 & 120 & 192 & 4 & 23 & 100 & 136 & 3 & 16 & 136 & 16 & 136 \\
\hline TRDP & 82 & 55 & 68 & 45 & 64 & 78 & 81 & 64 & 27 & 15 & 40 & 49 & 98 & 80 & 103 & 77 & 98 & 103 & 103 \\
\hline
\end{tabular}

Source: Authors' own calculation. 
(C)The Pakistan Development Review

54:4, Part II (Winter 2015) pp. 389-403

The study reveals that efficiency score resulted from DEA, is sensitive towards the choice of inputs, outputs, functional form and number of inputs and outputs. Based on the sensitivity of this technique, the study warns against single specification of DEA and recommends multiple specifications of DEA efficiency models to conclude whether a particular DMU is efficient or otherwise. It was noticed that two MFIs could yield the same efficiency score, however; their way to achieve efficiency was quite different from each other. The MFIs had used different channels, which were considered their strengths, such as controlling operational cost or optimal utilisation of loan officers and Assets. It was also noticed that MFIs were more efficient in their managerial and technical skills rather than the scale of operation of MIFs. It is recommended to estimate pure technical and scale efficiencies separately, to comprehend the sources of efficiency or inefficiency about various DMUs to identify peers for corresponding MFIs accordingly. The overall super efficiency result of an MFI, based on collective social and financial output variables (variable 1, 2, 3, and 4), is at least as efficient as financial or social super efficiency models for that MFI. Increasing the number of input and output variables changes the efficiency score of DMUs. This is evident from Tables 2 and 3. The higher the number of input and output variables, the higher the efficiency chance for an MFI and vice versa. In this case the estimation of super efficiency is important along with technical and scale efficiencies. This allows the researchers to rank the MFIs, based on super efficiency score. Technical and scale efficiency in isolation cannot rank MFIs according to their corresponding efficiency levels.

\section{REFERENCES}

Armendáriz, Beatriz, and Jonathan Morduch (2010) The Economics of Microfinance. MIT press.

Banker, Rajiv D. and Robert M.Thrall (1992) Estimation of Returns to Scale Using Data Envelopment Analysis. European Journal of Operational Research 62:1, 74-84.

Banker, Rajiv D., Abraham Charnes, and William Wager Cooper (1984). Some models for estimating technical and scale inefficiencies in data envelopment analysis. Management Science 30:9, 1078-1092.

Berger, Allen N. and David B.Humphrey (1997). Efficiency of Financial Institutions: International Survey and Directions for Future Research. European Journal of Operational Research 98:2, 175-212.

Charnes, Abraham, William W. Cooper, and Edwardo Rhodes (1978) Measuring the Efficiency of Decision Making Units. European Journal of Operational Research 2:6, 429-444.

Christen, Robert Peck and Deborah Drake (2002) Commercialisation: The New Reality of Microfinance. The Commercialisation of Microfinance: Balancing Business and Development 2-20.

Cinca, C. Serrano and C. Mar.Molinero (2004) Selecting DEA Specifications and Ranking Units via PCA. Journal of the Operational Research Society 55:5, 521-528.

Coelli, Tim, D. Rao and G. Battese (1998) An Introduction to Efficiency and Productivity Analysis. Kulwar Academic Publishers, Massachusetts, USA.

Engberg-Pedersen, Lars, and Helle Munk Ravnborg (2010) Conceptualisations of Poverty. DIIS Reports/Danish Institute for International Studies. 
Gonzalez, Adrian (2007) Efficiency Drivers of Microfinance Institutions (MFIs): The Case of Operating Costs. Microbanking Bulletin 15.

Gutiérrez, B., C. Serrano-Cinca, and C. Mar. Molinero (2007) Social Efficiency in Microfinance Institutions. Journal of the Operational Research Society 60:1, 104119.

Gutierrez, Jorge and Beatriz Goitisolo Lezama (2011) Profitability and Social Performance of Microfinance Institutions: Empirical Evidence of Relations between Different Types of Variables. reviSta de economía mundial 27, 189-214.

Gutiérrez-Nieto, Begoña, Carlos Serrano-Cinca, and C. Mar. Molinero (2007) Social Efficiency in Microfinance Institutions. Journal of the Operational Research Society 60:1, 104-119.

Gutierrez-Nieto, Begona, Carlos Serrano-Cinca, and Cecilio Mar Molinero (2007) Microfinance Institutions and Efficiency. Omega 35:2, 131-142.

Haq (2008) Microfinance Industry Assessment: A Report on Pakistan. Islamabad Pakistan Microfinance Network (PMN).

Haq, Skully, Michael, and Shams Pathan (2010) Efficiency of Microfinance Institutions: A Data Envelopment Analysis. Asia-Pacific Financial Markets 17:1, 63-97.

Hassan, M. Kabir, and Benito Sanchez (2009) Efficiency Analysis of Microfinance Institutions in Developing Countries. Networks Financial Institute at Indiana State University Working Paper, 12.

Hulme, and Andrew Shepherd (2003) Conceptualising Chronic Poverty. World Development, 31:3, 403-423.

Kabir, Hassan and Sanche Benito (2009) Efficiency Analysis of Microfinance Institutions in Developing Countries. Networks Financial Institute Working Paper.

Khodabakhshi, M. (2007) A super-efficiency Model based on Improved Outputs in Data Envelopment Analysis. Applied Mathematics and Computation 184:2, 695-703.

Kokkinou, Aikaterini (2010) A Note on Theory of Productive Efficiency and Stochastic Frontier Models. European Research Studies Journal 13:4, 109-118.

Ledgerwood, Joanna (1999) Microfinance Handbook: An Institutional and Financial Perspective: World Bank Publications.

Lovell, CAK and APB Rouse (2003) Equivalent Standard DEA Models to Provide Super-efficiency Scores. Journal of the Operational Research Society 54:1, 101-108.

Mamiza Haq, Michael, Skully and Shams Pathan (2010) Efficiency of Microfinance Institutions: A Data Envelopment Analysis. Asia-Pacific Financial Markets 17:1, 6397.

Mixmarket (2012) www.mixmarket.org.

Qayyum, Abdul, and Munir Ahmad (2006) Efficiency and Sustainability of Micro Finance Institutions in South Asia. South Asian Network of Economic Research Institutes (SANEI).

Rhyne, Elisabeth, and Robert Christen (1999) Microfinance Enters the Marketplace: USAID.

Ruggiero, John (2011) Introduction Frontiers in Major League Baseball (pp. 1-5): Springer.

State Bank of Pakistan (2011) Microfinance Department Strategic Framework for Sustainable Microfiance in Pakistan. Karachi: State Bank of Pakistan. 
Scheel, Holger (2000) EMS: Efficiency Measurement System User's Manual. Operations Research and Witshaftinsformetik. University of Dortmund, Germany.

Shiu, Alice (2002) Efficiency of Chinese Enterprises. Journal of Productivity Analysis $18: 3,255-267$.

Worthington, Andrew (1999) Performance Indicators and Efficiency Measurement in Public Libraries. Australian Economic Review 32:1, 31-42. 